\title{
Electrochemical Nitration of Naphthalene in Micellar Systems
}

\author{
Mariana N. Cortona, Nelio R. Vettorazzi, Juana J. Silber, \\ and Leonides E. Sereno* \\ Departamento de Química y Física. Universidad Nacional de Río Cuarto, Estafeta \\ Postal N 9, Río Cuarto, (5800) Córdoba, Argentina
}

Received: June 30, 1996; December 5, 1996

\begin{abstract}
Foi estudada a nitração do Naftaleno (NapH) em um eletrodo de Pt em soluções aquosas de NaNO2, na ausência e na presença de Brij 35, um surfactante não-iônico. O comportamento eletroquímico dos reagentes $\mathrm{NapH}$ e NaNO2 e de suas misturas foi investigado por voltametria cíclica para determinar as condições de eletrólise. A corrente de pico do NapH decresce monotonamente com a concentração de $\mathrm{NaNO} 2$, indicando que o produto da oxidação do íon $\mathrm{NO}^{-}$ interage com o $\mathrm{NapH}^{\bullet+}$. Foram realizadas eletrólises a potencial controlado e os produtos foram analisados por HPCL.

$\mathrm{Na}$ solução micelar foram obtidos 1-nitronaftaleno, 2-nitronaftaleno, 1,2-naftoquinona, 1,4-naftoquinona e 1,1'-Binaftilo (BinapH) enquanto que, na falta de Brij 35, somente foram detectados naftoquinonas e BinapH. A maior seletividade para 2-nitronaftaleno em comparação com meios homogêneos não-aquosos pode ter sido induzida pelo microambiente nas micelas.
\end{abstract}

The nitration of naphthalene $(\mathrm{NapH})$ at a Pt electrode in $\mathrm{NaNO}_{2}$ aqueous solutions in the absence and presence of a non-ionic surfactant, Brij 35, was studied. The electrochemical behavior of the reactants $\mathrm{NapH}$ and $\mathrm{NaNO}_{2}$ and their mixture was investigated by cyclic voltammetry to determine their electrolysis conditions. The peak current of $\mathrm{NapH}$ decreases monotonically with the $\mathrm{NaNO}_{2}$ concentration, indicating that the oxidation product of $\mathrm{NO}_{2}{ }^{-}$ ion interacts with $\mathrm{NapH}^{*+}$. Controlled potential electrolysis were carried out and the products were analyzed by HPLC. 1-nitronaphthalene, 2-nitronaphthalene, 1,2-naphthoquinone, 1,4-naphthoquinone and 1,1'-Binaphthyl (BinapH) were obtained in the micellar solution while in the absence of Brij 35 only naphthoquinones and BinapH were detected. The higher selectivity for 2- $\mathrm{NO}_{2} \mathrm{NapH}$ in comparison to non-aqueous homogeneous media may be induced by the micelles microenvironment.

Keywords: electro oxidation, micelles, nitration, naphthalene

\section{Introduction}

Electrochemistry on micelles has mostly developed in the last twenty years ${ }^{1}$. Monomeric molecules of amphiphilic compounds (tensoactives) possess regions of hydrophilic and hydrophobic character. In aqueous solutions, aggregates of these monomeric molecules (organized structures or micelles) can be reached when the monomeric concentration exceeds a critical value or critical micelle concentration $(\mathrm{cmc})^{2}$.

An important feature of these so-called microheterogeneous systems is that by careful election of the amphiphilic molecule and making use of the mode of distribution and location of solutes in the aggregates, it is possible to organize reactants at a microscopic (molecular) level ${ }^{3}$. Probably, the most important property of micellar solutions is their capacity to solubilize water-insoluble compounds, a process described by the dynamic equilibrium monomer-micelle in the action mass model ${ }^{4}$. The solubilization phenomenon is very important in chemistry, industry and biology 5 .

The nature of the micelle-substrate interaction determines the substrate electrochemical behavior ${ }^{6}$. Moreover, micellar effects have been studied from various perspectives, such as cmc and diffusion coefficients determinations ${ }^{5,7}$, 
electrode kinetic and thermodynamic parameters ${ }^{8}$, solubilization $^{9}$, catalysis ${ }^{1,10}$, electrosynthesis ${ }^{11}$, and electrode adsorption $^{12}$.

In a previous article we reported a mechanistic study of the nitration of naphthalene (NapH) by its electrochemical oxidation in the presence of nitrite ion in acetonitrile soluti$\mathrm{on}^{13}$. In the present communication, similar experiments are reported in aqueous solution where the non-ionic surfactant, Brij 35, was used to solubilize naphthalene in water. The electrosynthesis of nitro derivatives was performed by controlled potential electrolysis (CPE) on Pt electrodes. The product distribution was analyzed by high performance liquid chromatography (HPLC).

\section{Experimental}

Naphthalene (NapH) from Fluka AG was purified by sublimation prior to use. 1-Nitronaphthalene $\left(1-\mathrm{NO}_{2} \mathrm{NapH}\right)$ was synthesized from $\mathrm{NapH}$ with $53 \%$ $\mathrm{HNO}_{3}$ in acetic anhydride ${ }^{14}$, and recrystallized from ethanol- water mixtures (mp. $61 \pm 0.2^{\circ} \mathrm{C}$ ). 2-Nitronaphthalene $\left(2-\mathrm{NO}_{2} \mathrm{NapH}\right)$ from Aldrich was recrystallized five times from ethanol + water mixtures, and then sublimated (mp. $78.5 \pm 0.2{ }^{\circ} \mathrm{C}$ ). 1,2-Naphthoquinone (1,2-NaphQ), Aldrich was used as received. 1,4-Naphthoquinone (1,4-NaphQ), Fluka was recrystallized from ethanol (mp. $128.2 \pm 0.2^{\circ} \mathrm{C}$ ). 1,4-Dinitrobenzene (Fluka) was recrystallized three times from acetone (mp $173 \pm 0.2{ }^{\circ} \mathrm{C}$ ) and used as the internal standard in HPLC. The other reagents, $\mathrm{NaNO}_{2}$ (Merck p.a. min. 99\%), $\mathrm{NaClO}_{4}$ (Merck p.a. min. 99\%), and Brij35 (poly(oxyethylen) ${ }_{23}$ lauryl ether, Merck) were analytical grade and used as received. Brij 35 is a non-ionic surfactant whose $\mathrm{cmc}$ is $0.65 \mu \mathrm{M}$ and aggregation number is 40 , at $25^{\circ} \mathrm{C}$. HPLC analyses were performed in a Varian 5000 chromatograph with a MicroPak MCH-10 column and an isocratic 30:70 mixture of triply distilled water and methanol (Sintorgan, HPLC, water content $0.05 \%$ ) as the mobile phase at a flow rate of $0.5 \mathrm{~mL} / \mathrm{min}$. A Varian 2550 detector was used. The retention times in minutes were 8.79 for 1,2-NaphQ, 11.53 for 1,4-NaphQ, 21.51 for $1-\mathrm{NO}_{2} \mathrm{NapH}$, 23.65 for $2-\mathrm{NO}_{2} \mathrm{NapH}$, and 25.89 for $\mathrm{NapH}$.

The standard solutions of $\mathrm{NapH}$, nitro derivatives and other products were prepared by weighing. The exact concentration of NapH was determined by UV spectroscopy $\left(\lambda_{\max }=276 \mathrm{~nm}, \log \varepsilon=3.75\right)$ in a Hewlett-Packard HP 8452 spectrophotometer.

For cyclic voltammetry $(\mathrm{CV})$ and CPE measurements, a potentiostat-galvanostat EG\&G PAR model 273 was employed. The current and potentials were registered either on an X-Y EG\&G PAR model RE 0150, x-t REC 61 Servograph Radiometer recorder or with a Keithley 194A high speed voltmeter connected to a PC computer. Conventional three-compartment Pyrex cells were used for $\mathrm{CV}$ and $\mathrm{CPE}$ experiments. The cell for CPE was efficiently agitated by vertical hydrodynamic movements of the electrode support. The working electrodes were Pt disks of variable areas for $\mathrm{CV}$, and Pt electrodes of larger areas, $c a .4 \mathrm{~cm}^{2}$, for CPE experiments. The counter electrode was a stainless steel foil with a large area. All the potentials were referred to a saturated calomel electrode (SCE) and were corrected for iR drop by positive feedback techniques. The experiments were performed at $20^{\circ} \mathrm{C}$.

\section{Results and Discussion}

\section{Control experiments in the absence of Brij 35}

The solubility of $\mathrm{NapH}$ in aqueous solutions is low (i.e., $1.58 \times 10^{-4} \mathrm{M}$ at $20^{\circ} \mathrm{C}$ ), as determined by UV spectroscopy. In the presence of $\mathrm{NO}_{2}^{-}$ion, no changes in the aqueous solubility were detected. Cyclic voltammograms showed only the oxidation peak of nitrite, but the $\mathrm{NapH}$ oxidation occurred at $1.4 \mathrm{~V}$ because a saturated solution of $\mathrm{NapH}$ without nitrite decreased the UV $276 \mathrm{~nm}$ band after EPC. When a saturated solution of $\mathrm{NapH}+1 \times 10^{-2} \mathrm{M} \mathrm{NaNO}_{2}$ was electrolyzed at $1.4 \mathrm{~V}$, no nitration products were detected. At this potential value, $\mathrm{NO}_{2}{ }^{-}$ion oxidation is very important, but the reaction between $\mathrm{NapH}^{*+}$ and $\mathrm{NO}_{2}$ is very slow. The faster reaction occurs between $\mathrm{NapH}^{\circ+}$ and $\mathrm{H}_{2} \mathrm{O}$, to give only quinonic products $(1,2-\mathrm{NaphQ}, 1,4-\mathrm{NaphQ})$, as were detected by HPLC.

\section{Solubility of Naphthalene in micellar solutions}

In order to obtain evidence of $\mathrm{NapH}$ distribution between water and Brij 35 micelles, the partition parameter $\left(\mathrm{K}_{\mathrm{p}}\right)$ was evaluated from the solubility measurements, following a previously described procedure ${ }^{15,16}$.

$\mathrm{K}_{\mathrm{p}}$ is defined as:

$$
\mathrm{K}_{\mathrm{p}}=\frac{[\mathrm{NapH}]_{\mathrm{Ws}}}{[\mathrm{NapH}]_{\mathrm{M}}}=\frac{[\mathrm{NapH}]_{\mathrm{Ws}}}{[\mathrm{NapH}]_{\mathrm{MS}}+[\mathrm{NapH}]_{\mathrm{WS}}}
$$

where $[\mathrm{NapH}]_{\mathrm{WS}}$ and $[\mathrm{NapH}]_{\mathrm{MS}}$ represent the solubilities of $\mathrm{NapH}$ in water $/ 0.4 \mathrm{M} \mathrm{NaClO}_{4}$ and in the micellar solution, water $/ 0.4 \mathrm{M} \mathrm{NaClO}_{4} / \mathrm{Brij}_{3} 35\left(2.5 \times 10^{-2} \mathrm{M}\right)$, respectively. $[\mathrm{NapH}]_{\mathrm{M}}$ represents the $\mathrm{NapH}$ bound to the micelle. This method gives the value of $\mathrm{K}_{\mathrm{p}}$ at NapH saturation concentration and does not permit studies at different $\mathrm{NapH}$ concentrations below this solubility value. The $\mathrm{NapH}$ water solubility is $[\mathrm{NapH}]_{\mathrm{WS}}=1.58 \times 10^{-4} \mathrm{M}$ and in the micellar medium $[\mathrm{NapH}]_{\mathrm{MS}}=6.17 \times 10^{-3} \mathrm{M}$ giving a $\mathrm{K}_{\mathrm{p}}=0.026$. This means that $\mathrm{NapH}$ is almost completely solubilized in the micelle subphase at saturation. Thus, it is expected that under the electrolysis conditions, the $\mathrm{NapH}$ solubilization is even more favorable because the total substrate concentration is $2 \times 10^{-3} \mathrm{M}$.

\section{Cyclic Voltammetry}

$\mathrm{NaNO}_{2}$ 

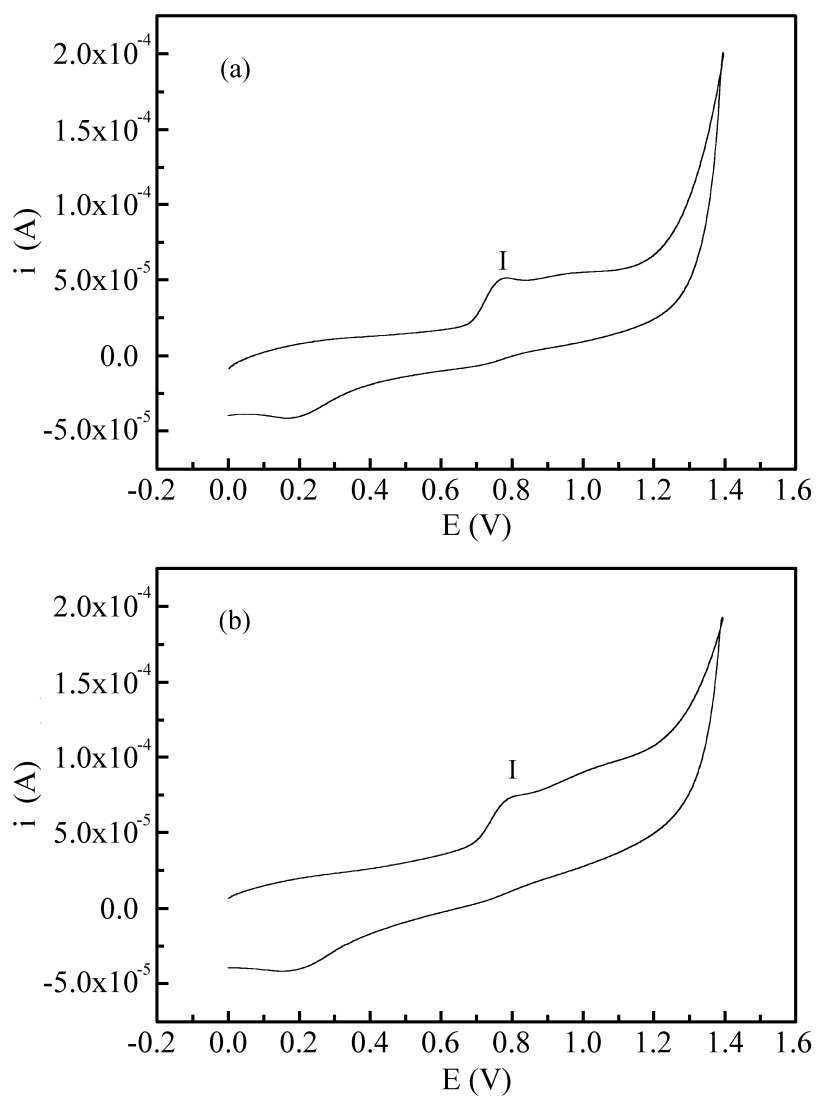

Figure 1. Cyclic voltammogram of the $\mathrm{NaNO}_{2}$ oxidation a) in aqueous solution; b) in micellar solution, [Brij 35] $=0.025 \mathrm{M},\left[\mathrm{NaNO}_{2}\right]=$

The electrochemical oxidation of the nitrite ion in aqueous solution ${ }^{17}$ is well established. Figure 1 shows the cyclic voltammograms obtained in aqueous solution (a) and with Brij 35 (b); in both cases only one peak at $E_{p, a}=0.800 \mathrm{~V}$ is detected in the anodic scan. No cathodic current is observed when the scan is reversed. This fact indicates a chemical complication coupled to a first charge transfer. In aqueous and micellar media the $\mathrm{CV}$ patterns are similar, indicating no interaction of $\mathrm{NO}_{2}{ }^{-}$ion with Brij 35 micelles, as expected for an ionic substrate. This implies that $\mathrm{NO}_{2}^{-}$ion is not partitioned into the micelles. In both cases, the peak current varies linearly on $\mathrm{v}^{1 / 2}$ and on the $\mathrm{NO}_{2}{ }^{-}$concentration, but in the micellar medium the current is only about $80 \%$ of the value in the aqueous system. This fact can be explained by an increase of the viscosity of the micellar system ${ }^{18}$.

The electrochemical reaction in aqueous solution has been interpreted in terms of a complex mechanism ${ }^{17}$ (Eqs. 2-4):

$$
\begin{aligned}
& 2\left(\mathrm{NO}_{2}^{-} \longrightarrow \mathrm{NO}_{2}+1 \mathrm{e}^{-}\right) \\
& 2 \mathrm{NO}_{2}+\mathrm{H}_{2} \mathrm{O} \longrightarrow \mathrm{NO}_{3}^{-}+\mathrm{NO}_{2}^{-}+2 \mathrm{H}^{+} \\
& \mathrm{NO}_{2}^{-}+\mathrm{H}_{2} \mathrm{O} \longrightarrow \mathrm{NO}_{3}^{-}+2 \mathrm{H}^{+}+2 \mathrm{e}^{-}
\end{aligned}
$$

The principal product formed in the first charge transfer reaction is $\mathrm{NO}_{2}$. Subsequently, $\mathrm{NO}_{2}$ suffers disproportionation to give $\mathrm{NO}_{3}^{-}$and $\mathrm{NO}_{2}^{-}$ions (Eq. 3), in an irreversible way. The rate constant value obtained by electrochemical measurement ${ }^{17}$ is $\mathrm{k}=4 \times 10^{6} 1 \mathrm{~mol}^{-1} \mathrm{~s}^{-1}$. Hence, the $\mathrm{NO}_{2}$ concentration is only appreciable in a reaction layer near the electrode surface. This layer can be estimated to be less than the thickness of the diffusion layer of $\mathrm{NO}_{2}^{-}$ion ${ }^{19}$. However, the $\mathrm{NO}_{2}$ concentration profile is enough to react with the NapH radical cation, $\mathrm{NapH}^{*+}$ (see below). Therefore, under voltammetric conditions the overall electrode process is given by Eq. 4. In CPE experiments in a unbuffered medium the reaction of the $\mathrm{NO}_{2}^{-}$ion with $\mathrm{H}_{3} \mathrm{O}^{+}$gives:

$$
\mathrm{NO}_{2}{ }^{-}+\mathrm{H}_{3} \mathrm{O}^{+} \rightleftharpoons \mathrm{HNO}_{2}+\mathrm{H}_{2} \mathrm{O}
$$

The $\mathrm{pK}_{\mathrm{a}}$ value $^{20}$ of this reaction is 3.25 , but this fact is not important for CPE conditions since the proton transfer kinetic in water is fast. In order to confirm this hypothesis, the $\mathrm{CPE}$ of $\mathrm{NO}_{2}^{-}$solution with Brij 35 was performed at $1.45 \mathrm{~V}$. The current decayed exponentially with time at a value near the blank current, and the $\mathrm{pH}$ of the solution decreased from 6.31 to around 1.1. The apparent electron number $\mathrm{n}_{\text {app }} / 1.8$ Faraday per mole of $\mathrm{NO}_{2}^{-}$ion is in agreement with Eq. 4. These facts show that the $\mathrm{HNO}_{2}$ concentration is negligible at the end of the electrolysis, supporting our hypothesis.

\section{Naphthalene}

A typical cyclic voltammogram of NapH in Brij 35 solution is illustrated in Fig. 2. An oxidation wave $(\mathrm{E}=1.40 \mathrm{~V})$ due to the NapH oxidation to give $\mathrm{NapH}^{*+}$ is observed on the first sweep. This wave is not defined as a peak probably due to the $\mathrm{O}_{2}$ evolution. It is highly irreversible and no complementary cathodic peak is observed even at $50 \mathrm{~V} \mathrm{~s}^{-1}$. This is an indication of a very short life time for $\mathrm{NapH}^{\circ+}$ and/or a fast follow-up reaction coupled to the

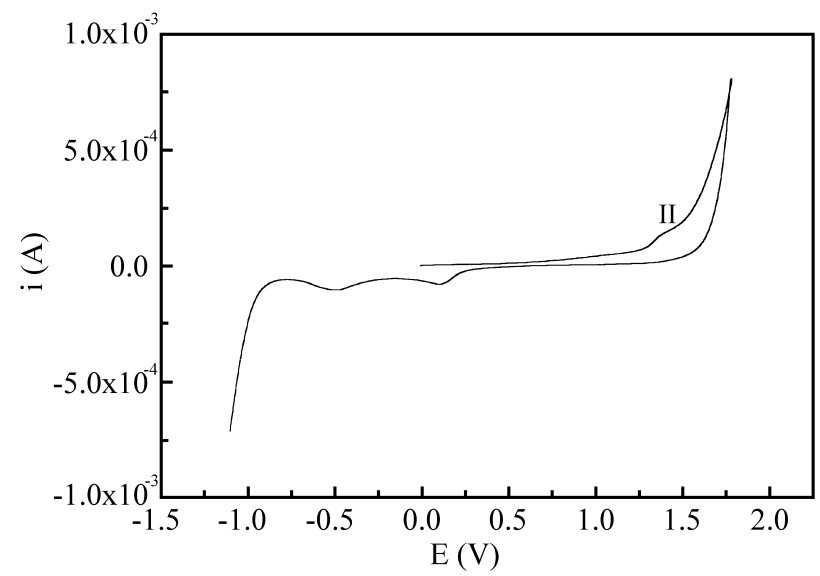

Figure 2. Cyclic voltammogram for $\mathrm{NapH}$ oxidation in micellar solution. $[\mathrm{NapH}]=5.5 \times 10^{-3} \mathrm{M},[$ Brij 35$]=0.025 \mathrm{M}$. The other conditions 
charge transfer, as observed for the $\mathrm{NapH}^{*+}$ stability in another organic medium ${ }^{13}$. Assuming that $\mathrm{NapH}$ is only in the micellar subphase, its microenvironment would be more like an organic solvent and a similar behavior could be expected.

The current limit $i_{L I}$ shows a linear dependence on $v^{1 / 2}$ in the sweep rates range from 0.01 to $0.3 \mathrm{~V} \mathrm{~s}^{-1}$. This observation reinforces the idea of a fast reaction coupled to the charge transfer. Typical reactions of the aromatic radical cations are the dimerization and even further polimerization reactions ${ }^{21}$. The more probable dimerization product of

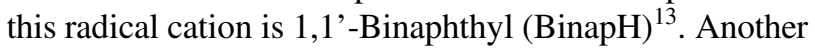
possibility is that $\mathrm{NapH}^{-+}$reacts with a nucleophile, water for example, to give oxygenate substitution products such as quinones ${ }^{22}$.

In the negative sweep, two peaks are observed. The peak at $0.15 \mathrm{~V}$ is assigned to the $\mathrm{PtO}$ reduction in this medium, as confirmed by blank experiments (without $\mathrm{NapH}$ ). The other peak at $-0.40 \mathrm{~V}$ is assigned to the solvated protons released by the dimerization reaction of $\mathrm{NapH}^{*+}$, as confirmed by the addition of perchloric acid to the solution. No new peak was detected by cycling between -1.10 and $1.75 \mathrm{~V}$. Therefore, the electrooxidation of $\mathrm{NapH}$ in micellar medium can be interpreted by the following global process:

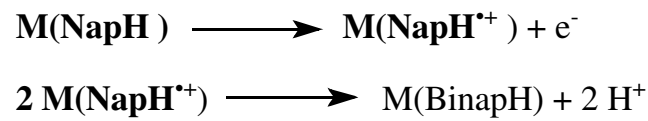

$$
\mathbf{M}\left(\mathbf{N a p H}^{++}\right) \stackrel{\mathrm{H}_{2} \mathrm{O}}{\longrightarrow} \mathrm{M}(\mathrm{Q})+6 \mathrm{H}^{+}+5 \mathrm{e}^{-}
$$

Where $\mathrm{M}(\mathrm{NapH}), \mathrm{M}\left(\mathrm{NapH}^{*+}\right), \mathrm{M}(\mathrm{BinapH}), \mathrm{M}(\mathrm{Q})$ stand for $\mathrm{NapH}, \mathrm{NapH}^{\circ+}$, BinapH, and Quinone in the micelle subphase, respectively.

\section{$\mathrm{NaNO}_{2}+\mathrm{NapH}$ solution}

A typical cyclic voltammogram obtained when both substrates are in solution is illustrated in Fig. 3. Two well-defined peaks are observed which correspond to the $\mathrm{NO}_{2}^{-}$ion oxidation (peak I) and $\mathrm{NapH}$ oxidation (peak II). The peak potentials are the same as those of the separate substrates (Fig. $1 \mathrm{~b}$ and Fig. 2). The peak current $\mathrm{i}_{\mathrm{pI}}$ does not change with respect to its value in Figure 1b, however, the peak current for the NapH electrooxidation (peak II) changes when $\mathrm{NO}_{2}{ }^{-}$ion is present. Thus, to determine this dependence, systematic studies were carried out keeping $\mathrm{NapH}$ constant and changing the $\mathrm{NO}_{2}^{-}$ion concentration. In all cases, $i_{\mathrm{pI}}$ changes linearly with the concentration, but $\mathrm{i}_{\mathrm{pII}}$ decreases when $\mathrm{NO}_{2}{ }^{-}$increases (Fig. 4). This suggests that either the $\mathrm{NO}_{2}{ }^{-}$ion or its oxidation product interacts with $\mathrm{NapH}^{*+}$, changing its route of degradation, in agreement with similar results obtained in a non-aqueous system ${ }^{13}$.

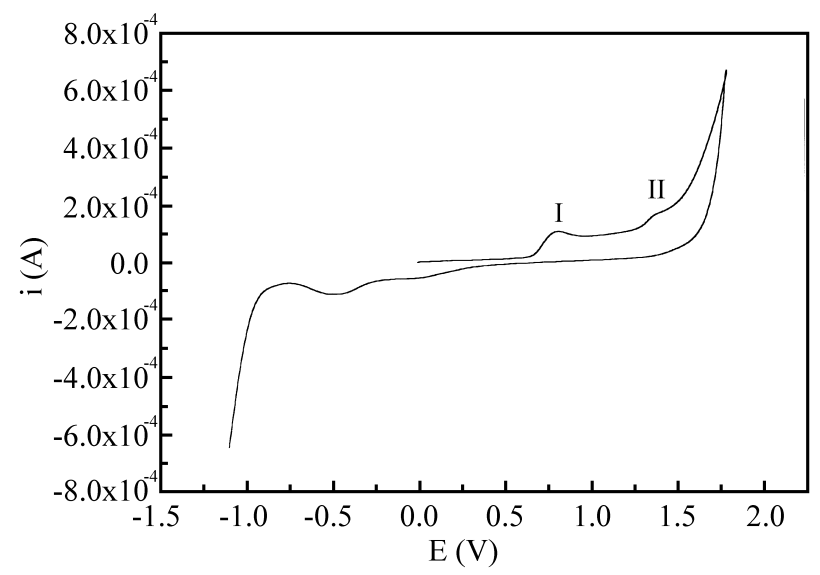

Figure 3. Cyclic voltammogram for $\mathrm{NapH}$ and $\mathrm{NaNO}_{2}$ oxidation in micellar solution. [Brij 35] $=0.025 \mathrm{M},[\mathrm{NapH}]=5 \times 10^{-3} \mathrm{M}\left[\mathrm{NaNO}_{2}\right]$ $=5 \times 10^{-3} \mathrm{M}$. The other conditions are the same as in Fig. 1

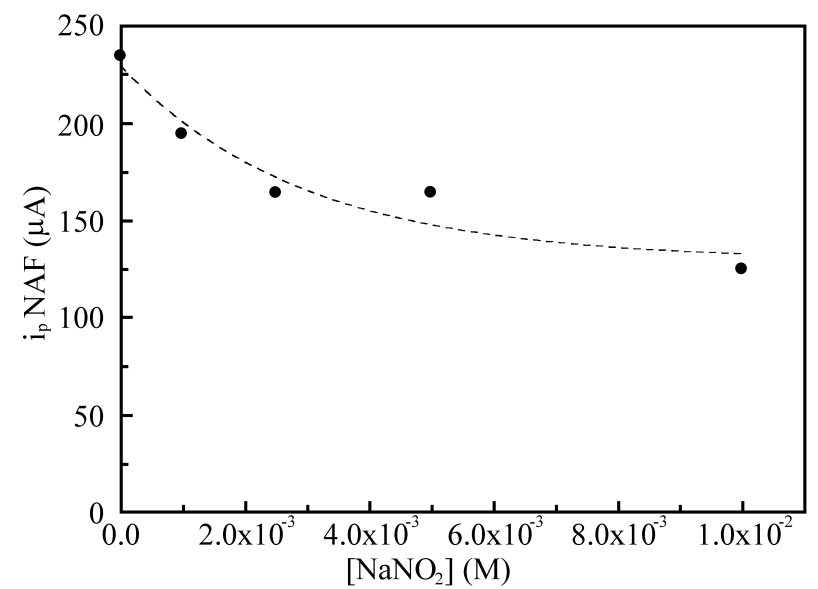

Figure 4. Dependence of $\mathrm{i}_{\mathrm{pII}}$ as a function of the $\mathrm{NO}_{2}{ }^{-}$ion concentration. $[\mathrm{NapH}]=5.5 \times 10^{-3} \mathrm{M}$, [Brij 35] $=0.025 \mathrm{M}$. The other conditions are the same as in Fig. 1

\section{Controlled-Potential Electrolysis (CPE)}

In view of the $\mathrm{CV}$ results reported above, $\mathrm{CPE}$ was performed for two different micellar solutions: (a) only $\mathrm{NapH}$ present, and (b) both substrates $\mathrm{NapH}+\mathrm{NaNO}_{2}$.

\section{a) CPE of NapH}

Following the conditions in Fig. 2, CPE of a $2 \times 10^{-3} \mathrm{M}$ $\mathrm{NapH}$ solution with $2.5 \times 10^{-2} \mathrm{M}$ Brij 35 and $0.4 \mathrm{M} \mathrm{NaClO}_{4}$ as the supporting electrolyte was performed at $1.45 \mathrm{~V}$. The initial colorless solution turned to pale yellow at the end of the electrolysis. The experiment was concluded when $\mathrm{NapH}$ was no longer detected by the HPLC technique. Under these conditions, the detected products are only 1,2and 1,4-NaphQ. However, the mass balance with respect to $\mathrm{NapH}$ suggests another product, probably the dimer BinapH or an insoluble oligomer. In addition, the $\mathrm{pH}$ of the solution decreased to $\mathrm{pH} / 2$, as expected when $\mathrm{H}^{+}$is released in chemical reactions (Eqs. 7 and 8). The electrolysis 
Table 1. Yield of products for $\mathrm{CPE}$ of $\mathrm{NapH}$ in different conditions.

\begin{tabular}{|c|c|c|}
\hline Product & Brij $35+\mathrm{NapH} / \%$ & Brij $35+\mathrm{NapH}+\mathrm{NaNO}_{2} / \%$ \\
\hline 1,2-NaphQ & 3.3 & 4.2 \\
\hline 1,4-NaphQ & 10.7 & 14.3 \\
\hline $1-\mathrm{NO}_{2} \mathrm{NapH}$ & -- & 32.4 \\
\hline 2- $\mathrm{NO}_{2} \mathrm{NapH}$ & -- & 2.0 \\
\hline BinapH & 43 & 23.6 \\
\hline
\end{tabular}

current decayed exponentially with time, and the $\mathrm{n}_{\text {app }} \cong 4.6$ per molecule of $\mathrm{NapH}$ was calculated at the end of the electrolysis. The $\mathrm{n}_{\mathrm{app}}$ value observed is consistent with the electrooxidation of NapH under these conditions to give quinones and binaphthyl or an oligomeric product.

Typical result fors this CPE are shown in Table 1.

\section{b) $\mathrm{CPE}$ of $\mathrm{NapH}+\mathrm{NaNO}_{2}$}

The possibility of the NapH nitration by the electro oxidation product of the $\mathrm{NO}_{2}^{-}$ion was explored by CPE performed at $1.2 \mathrm{~V}$. At this potential, only the $\mathrm{NO}_{2}^{-}$ion is electrolyzed. Under these conditions, no nitration nor quinonic products are detected by HPLC. This provides the evidence that $\mathrm{NapH}$ is not attacked by the intermediate product of the $\mathrm{NO}_{2}^{-}$ion electro oxidation. The absence of the quinonic and nitrated products would indicate that $\mathrm{NapH}^{\circ+}$ mediates in their formation. Thus, CPE was performed at $1.45 \mathrm{~V}$, and the products detected by HPLC were 1- $\mathrm{NO}_{2} \mathrm{NapH}, 2-\mathrm{NO}_{2} \mathrm{NapH}, 1,2-\mathrm{NaphQ}$, and 1,4-NaphQ. Also, the formation of BinapH was assumed, and its yield was calculated from the mass balance. Typical results are shown in Table 1. It should be noted that the ratio 1$\mathrm{NO}_{2} \mathrm{Naph} / 2-\mathrm{NO}_{2} \mathrm{NapH}$ is lower than that observed in previous studies in acetonitrile medium ${ }^{13}$, indicating a micellar effect that may be due to preferred orientations of the substrate in the organized media.

\section{Conclusions}

In aqueous systems in the presence of the $\mathrm{NO}_{2}^{-}$ion , no nitration is observed. $\mathrm{NapH}^{++}$reacts fast with water to form quinones. On the other hand, the electrogenerated $\mathrm{NO}_{2}$ (Eq. 2) decomposes, as shown in Eq. 3. Both reactions are faster than those of nitration.

In micellar systems, nitrated products are obtained. Probably, the micellar microstructure increases the $\mathrm{NO}_{2}$ solubilization in a micelle subphase, favoring its encounter with $\mathrm{NapH}^{*+}$. The ratio of 1- $\mathrm{NO}_{2} \mathrm{Naph} / 2-\mathrm{NO}_{2} \mathrm{NapH}$ is lower than in non-aqueous media, where the ratio is always greater than $50^{13}$. The higher yield of $2-\mathrm{NO}_{2} \mathrm{NapH}$ may be explained by intramolecular selectivity induced by the micelles microenvironment.

\section{Acknowledgments}

Financial support from the Consejo de Investigaciones Científicas y Tecnológicas de la Provincia de Córdoba (CONICOR) and Secretaría de Ciencia y Técnica de la Universidad Nacional de Río Cuarto is gratefully acknowledged. M. Cortona thanks CONICOR for a research fellowship.

\section{References}

1. Rusling., J.F. Acc. Chem. Res. 1991, 24, 75.

2. Fendler, J.H.; Fendler, E.J. In Catalysis in Micellar and Macromolecular Systems; Academic Press, N.Y., 1975.

3. Kalyanasundaram, K. In Photochemistry in Microheterogeneous Systems; Academic Press, London 1987, Chap. 1.

4. Fisher, L.R.; Oakenfull, D.G. Chem. Soc. Rev. 1977, $6,25$.

5. Texter, J.; Horch, F.R.; Qutubuddin, S.; Dayalan, E. J. Colloid Interface Sci. 1990, 135, 263.

6. McIntire, G.L.; Chiappardi, D.M.; Casselberry, R.L.; Blount, H.N. J.Phys. Chem. 1982, 86, 2632.

7. a) Zana, R.; Mackay, R.A. Langmuir 1986, 2, 109. b) Rusling, J.F.; Shi, Ch Ni; Kumosinski, T.F. Anal. Chem. 1988, 60, 1260. c) Mandal, A.B.; Nair, B.U.; Ramaswamy, D. Langmuir 1988, 4, 736. d) Mandalm, A.B.; Nair, B.U. J. Phys. Chem. 1991, 95, 9008.

8. a) Meyer, G.; Nadjo, L.; Saveant, J.M. J. Electroanal. Chem. 1981, 119, 417. b) Ohsawa, Y.; Shimazaki, Y.; Suga, K.; Aoyagui, S. J. Electroanal. Chem. 1981, 123, 409. c) Genies, M.; Thomalla, M. Electrochim. Acta 1981, 26, 829. d) Sayarh, S.B., Martre, A.M.; Mousset, G.; Pouillen, P. Electrochim. Acta 1983, 28, 1105. e) Georges, J. and; Desmettre, S. Electrochim. Acta 1984, 29, 521. f) Kaifer, A.E. and; Bard, A.J. J.Phys. Chem. 1985, 89, 4876. g) Mousty, C.; Devaux, B.; Mousset, G.; Pouillen, P.; Martinet, P. Electrochim. Acta 1985, 30, 1733. h) Quintela, P.A.; Diaz, A; Kaifer, A.E. Langmuir 1988, 4, 663.

9. Verniette, M.; Pouillen, P.; Martinet, P. Bull. Soc. Chim. Fr. 1984, 1, 141.

10. a) Franklin, T.C.; Iwunze, M. J. Electroanal. Chem. 1980, 108, 97. b) Thanos, I. J. Electroanal. Chem. 1987, 235, 131.

11. Laurent, E.; Rauniyar, G.; Thomalla, M. N. J. Chim. 1982, $11,515$.

12. Nikitas, P. J. Electroanal. Chem. 1993, 348, 59.

13. Cortona, M.N.; Vettorazzi, N.; Silber, J.J.; Sereno, L. J. Electroanal. Chem. 1995, 304, 245.

14. Davies, A.; Warren, K.D. J. Chem. Soc. 1969, B, 873.

15. Georges, J.; Desmettre, S. Electrochim. Acta. 1984, 29, 521.

16. Ohsawa, Y.; Aoyagui, S. J. Electroanal. Chem. 1982, $136,353$. 
17. (a) Vetter, K.J. In Electrochemical Kinetics; Academic Press, N.Y. 1967, 490. (b) Guidelli, R.; Pergola, F., Raspi, G. Anal. Chem. 1972, 37, 745.

18. McIntire, G.L.; Chiappardi, D.M.; Casselberry, R.L.; Blount, H.N. J.Phys. Chem. 1982, 86, 2632.

19. a) Feess, H.; Wendt, H. Ber. Bunsenges. Phys. Chem. 1981, 85, 914. b) Wendt, H. Angew. Chem. Int. Ed. Engl. 1982, 21, 256.
20. CRC Handbook of Chemistry and Physics, $75^{\text {th }}$ Ed.; Lide, D.R., Ed., CRC Press, 1995.

21. Waltman, J.; Bargon, J. Can. J. Chem. 1986, 64, 76.

22. a) Sioda, R. J. Phys. Chem. 1968, 72, 2322. b) Bard, A.J.; Ledwith, A.; Shine, E.J. In Advances in Physical Organic Chemistry; Gold, V.; Bethell, D., Eds.; Academic Press, London, 1976, Vol. 13. 